\title{
ONDE SE ESCONDE O DESEJO DE APRENDER DO ALUNO?
}

\author{
Ayrton Rodrigues Reis \\ Orion Penna e Souza
}

Educar está longe de ser aquilo pressuposto pelo processo de psicologização do cotidiano. A intervenção educativa, à diferença do adestramento capaz de desenvolver um savoir-faire natural, possibilita o desdobramento de um savoir-vivre artificial. (...) Em suma, educar é possibilitar uma filiação simbólica humanizante.

(LAJONQUIÈRE, 1999: 138).

\section{CONSIDERAÇÕES INICIAIS}

A pesquisa sobre a falta de desejo em sala de aula vem crescendo, já que é comum pensar que todo o sujeito se desenvolve, isto é, que no principio existiria uma espécie de não-sujeito ou substância, com pretensões de vir a ser, o que, com tempo e com esforço, consegue finalmente, devir tal. Em suma, o envolvido, na origem, acaba se envolvendo. Para Lajonquière, 1992, p. 151,

Não só antes de falar e de caminhar, mas antes mesmo de nascer empiricamente à vida, o sujeito já é objeto do discurso, do desejo e das fantasias de seus genitores que, por sua vez, são sujeitos assujeitados às estruturas lingüísticas, psicanalíticas e históricosociais. Sua concepção, embora deva-se à união de um óvulo a um espermatozóide, não é um fato natural uma vez que se trata de um acontecimento legislado. Com efeito, o encontro sexual entre $o$ macho e a fêmea da espécie humana está regulado (regulamentado) pela lei universal da proibição do incesto que estabelece as alianças possíveis e impossíveis entre, agora sim, homem e mulher".

Segundo Lacan (1978), o recalque originário é o processo que introduz o sujeito na corrente da cultura e da civilização, ensinando-o a substituir o real da existência (desejo de ser para a mãe) por um símbolo e uma lei (o pai e a família). Os interditos todos para os quais o homem precisará de um símbolo que os represente preexistem ao sujeito, estão na própria cultura e chegam a ele através da linguagem. Por essa razão, Lacan se refere à ordem do simbólico como algo que constitui o homem. É o homem que, de recalque em recalque, nela se insere. Assim sendo,

... o sujeito, se parece servo da linguagem, ele o é mais ainda de um discurso em cujo movimento universal seu lugar já está inscrito desde seu nascimento, ainda que seja sob a forma seu nome próprio. (Lacan, 1978, p. 226).

Ainda Lacan: 
O que está em questão no desejo é um objeto, não um sujeito. É neste ponto que reside aquilo que se pode chamar de o mandamento espantoso do deus do amor. Esse mandamento é, justamente, de fazer do objeto que ele nos designa algo que, em primeiro lugar, seja um objeto, e, em segundo lugar, um objeto diante do qual desfalecemos, vacilamos, desaparecemos como sujeito. Pois essa queda, essa depreciação, nós, como sujeito, é que a sofremos. (Lacan, 1992, p. 172).

\section{ALGUMAS CONSIDERAÇÕES SOBRE O DESEJO}

No início, o homem só tem de homem o status de animal vivo. Como tal, não passa de um ser de necessidades. Para conquistar sua identidade, será preciso que se torne ser de desejo, isto é, consciência desejante ou consciência de si. (DOR, 1989: 133).

O desejo, cuja função é a de ser um ponto de fixação através do qual o sujeito se afirma como existente, é sempre inconsciente e não está necessariamente relacionado a um objeto real. É desejo do Outro, da mãe, desejo de incesto, cerne do complexo de Édipo. A sua causa é um objeto parcial, e sua estrutura é um resto que escapa a qualquer articulação que o sujeito possa fazer. Caracterizado pela falta e pela lei, ele escapa à variabilidade inerente a seus objetos. No entanto, a lei não contradiz o desejo, ao contrário, o autoriza, na castração. 0 desejo é marcado pela falta e a castração simboliza a lei dessa falta. Assim, o desejo só aparece dissimulado sob a máscara da fantasia. Que é seu objeto e não a sua causa.

Não basta dizer que, na relação do sujeito com o objeto, o desejo implica uma mediação ou um intermediário reflexivo, se apenas está em questão, por exemplo, o sujeito se pensando, como ele se pensa, na relação de conhecimento com o objeto. Edificou-se, neste ponto, toda uma teoria do conhecimento, que a teoria do desejo é apropriada, precisamente para pôr em causa. Isso nos faria estremecer se outros, antes de nós, já não tivessem posto em causa o penso, logo sou cartesiano.

O assujeitamento do sujeito-aluno e sua motivação em sala de aula, no que tange ao ensino-aprendizagem de língua portuguesa dentro do sistema de ensino formal, vêm se esvaziando a olhos vistos.

O ensino de língua materna, no Brasil, está na UTI há muito tempo, ninguém ignora. Tem sido comum, infelizmente, a manutenção de estratégias de ensino ultrapassadas e inócuas entre nossos professores de $1^{\circ}$ e $2^{\circ}$ graus - mesmo entre aqueles que fazem cursos de reciclagem. (RICHTER, 2000:11).

É desnecessário dizer que a falta de motivação por parte do corpo discente vem crescendo de forma assustadora há muito tempo. O aluno, enquanto sujeito receptor de informações, já não condiz com o ensino desatualizado encontrado em muitas de nossas escolas. É preciso, pois, aliar o ensino à cultura para assim despertar no campo do sujeito-aluno o desejo em aprender. 
Em Bonneuil entende-se por cultura desde tirar o capim do jardim, cultivar batatas junto a um dos vizinhos da escola, dar descarga no banheiro ou participar das atividades que o Musée du Louvre costuma ofertar para todas as crianças sem distinção de cor, religião, sexo, estado civil ou psíquico. (LAJONQUIÈRE, 1999:123).

Fica claro que quando ensinamos algo a uma criança colocamos em ato nossa fantasmática, isto é, a iniciativa do ato cai na conta do desejo do adulto em função educativa. Pode-se dizer ainda que é transmitida uma lógica operativa que transcende um campo fantasmático no interior do qual o sujeito está tomado como sujeito desejante, uma vez que se trata de um pedaço da cultura, de um fragmento do liame social.

Com efeito, a motivação por parte do aluno poderá ser resgatada através da teoria de Jacques Lacan e seus Quatro Discursos, já que para este autor o inconsciente estruturado como linguagem, possui dois campos: o do sujeito e o do Outro. No Outro, situa-se a cadeia de significantes que comanda o que vai presentificar-se do sujeito, é o campo desse vivo onde o sujeito pode aparecer. A pulsão se manifesta do lado desse vivo, chamado à subjetividade.

Segundo Baldino, há tentativas de buscar amparo na psicanálise para resolver problemas de ansiedade no ensino ou na aprendizagem, sempre sob a perspectiva de uma certa esperança.

Aos que tomam o contato aluno/pesquisador (ou professor) como forma primária de dados da pesquisa em microcognição, é preciso lembrar que, restringir os observáveis aos enunciados, verbais ou gestuais (Piaget), mesmo que contextualizados (Vygotsky), é esquecer que toda resposta é, antes de tudo, um encadeamento de falas (discurso de um sujeito diante da demanda do Outro). Segundo Lacan, quando fala, o sujeito se submete a um processo complexo em que se imbricam simultaneamente o imaginário, o simbólico e o real.

Dentro desta ótica com os quatro discursos de Lacan, ou seja, o discurso de mestre, o discurso universitário, o discurso do analista e o discurso da histérica, não se pretende, desta forma, orientar a uma prática em sala de aula a partir da psicanálise, nem, muito menos, de psicanalisar o aluno. Tenta-se, mais precisamente, obter elementos para compreender e explicar isso que já se faz há bastante tempo, a saber, a aprendizagem enquanto experiência.

Sabe-se que há atualmente no Brasil um sintoma que atinge os processos culturais de uma forma geral: a falência da transmissão na relação professoraluno. Poderíamos pensar que, na verdade, através das colocações de Sigmund Freud, estes processos não são novos, e revelam o que já se sabe: governar, psicanalisar e educar são profissões impossíveis.

No entanto, a situação que existia na época de Freud é bastante distinta daquela que se apresenta contemporaneamente. Antes, ainda se tentava ensinar, atingir o 
aluno através de um contexto onde o saber era elaborado de alguma forma. Hoje, na rede pública brasileira, há uma descrença profunda em relação aos próprios processos de transmissão. O professor não acredita mais que ele possa ensinar e os alunos que eles possam aprender.

Os professores e alunos atuais vêm tecendo o seu "ser" através de determinadas informações, ou seja, daquilo que eles nomeiam "ser" professor e "ser" aluno. Entretanto, com isto ficam capturados no circuito das próprias representações estabelecidas, escapando de um processo de implicação ainda maior: as dificuldades do não-saber-fazer.

Lacan, através de sua obra, nos apresenta uma outra resposta para as falhas de transmissão atuais no que se refere ao ato de educar: não houve uma verdadeira transferência de trabalho.

A teoria da transferência de Lacan tem sem dúvida seu suporte teórico na diferença entre o imaginário e o simbólico. "Na medida em que a transferência é sempre um fenômeno imaginário, o que o analista tem que fazer é quebrá-lo, transformar a relação imaginaria em simbólica". (ETCHEGOYEN, 1987: 78).

Segundo as teorias lacanianas, educar não é levar o aluno e o professor a se identificarem através dos circuitos escolares ou se apropriarem do saber, tornando-os "seus". Educar é perceber que o ensino nos remete à própria cultura, à uma nova forma de ver o social e o individual. Ensinar é estabelecer referências.

Lacan nos propicia uma outra resposta, distinta daquela estabelecida pelos psicopedagogos: ensinar é gerar transferência de trabalho. Ensinar é pôr os alunos a trabalhar, fazendo-os ir em busca do que eles não sabem.

Mas, qual a diferença entre as duas propostas? A Psicopedagogia faz uma leitura do mundo como se a resposta dos sujeitos se encontrasse no significado, no significante e no sentido. Isto é, ela acredita que haja a resposta. Para a Psicanálise, este contexto se explicita de uma outra forma. O saber é da ordem do semblante. Ele se encontra atrelado ao processo do sujeito. Não se trata mais de um saber universal. Ele se apresenta sob várias vestimentas. Todas são semblantes, nenhuma é a coisa. Por isso, É preciso que nós não confundamos saber e verdade. O saber que a escola apresenta não é verdadeiro. Ele também é mais uma forma, semblante do saber. Por exemplo, uma das faces do saber na escola é o saber científico. O saber que o professor apresenta pode ser tomado como sendo a ciência pelos alunos, mas ele não é a ciência. O saber do cientista tem outra estrutura, apresenta uma outra articulação proposicional, necessitando ser resgatado em seu contexto específico. O que vai determinar a verdade é a lógica proposicional que ela apresenta. Ou seja, é a partir da emissão do discurso e, em decorrência, da sua análise bem como da análise dos seus efeitos que se pode saber se um saber é verdadeiro ou não.

Portanto, o relato de uma experiência pedagógica em sala de aula na qual se apresentam duas vivências diferenciadas nos propicia uma reflexão sobre o papel do "eu" aluno diante do texto. Uma, utilizando-se de numa metodologia tradicional 
onde o aluno não é levado a pensar; outra, após a aplicação da pesquisa-ação onde o aluno produz seu texto ou sua leitura baseado num ensino estimulativo, nos cai bem neste momento. A "matéria" abordada, então, em sala de aula foi o uso da polifonia, a qual serviu de base para esta pesquisa onde o sujeito não é dono do seu dizer e sendo assim, pode-se avaliar os processos investigativos no ensino-aprendizagem.

Por exemplo, a dificuldade dos alunos de Letras em trabalharem com polifonia, ou seja, a fragmentação do locutor em múltiplas vozes, algumas até com que ele não se identifica, relaciona-se à forma problemática de equacionamento da subjetividade encontrada no texto polifônico, que dificulta para os alunos discriminar a perspectiva do sujeito que fala. Ou seja, a subjetividade encontrada na polifonia é a capacidade de o locutor se propor como sujeito do seu discurso e ela se funda no exercício da língua como autoria, efetuando a síntese das vozes introjetadas no espaço do próprio discurso.

A dificuldade aparece quando se dá a passagem da transferência do conhecimento, dificuldade esta encontrada em grande parte de nossas escolas. $O$ silêncio sobre a dor da transmissão do conhecimento, o comportamento esquivo, evasivo em relação às angústias do convívio social e escolar, a intolerância dos valores da instituição em relação a seus membros são negações cognitivas que equivalem a verdadeiros ataques à construção da consciência. Ataques que acabam por esgarçar o tecido simbólico - aquele que apóia o campo psíquico do sujeito diante da manifestação do mundo e de sua beleza - e destroem a possibilidade da experiência emocional a ser recebida com algum prazer no interior da mente do indivíduo em estado nascente, criando um mundo interno cheio de objetos que são apenas coisas em si (objetos dissociados de seus respectivos sentidos afetivos), sem significado humano, símbolos sem a simbolização como processo. Aqui o intervalo entre a necessidade e o desejo está preenchido por essa dúvida em existir, por essa vacilação, por essa recusa, por essa preguiça letárgica característica das depressões sem sintoma visível (de expressão sub-clínica) mas cuja potência é desintegradora e destrói a esperança. Nesse estado de quase desistência de viver (muitas vezes maquiado por uma intensa atividade feita compulsivamente), formular tanto o desejo, quanto a necessidade implica, antes, em uma decisão íntima de vontade ligada ao ser de cada um de nós, implica em dizer um "sim" pleno de certeza, mesmo que silenciosamente, como se faz um ato de contrição, implique uma afirmativa simples: sim, vale a pena viver. E, mais que isto, vale a pena viver sem exaurir a paciência e o estômago do outro, sem tornar-se um fardo para os outros, sem querer ser o destino funesto dos outros.

A escolha da psicanálise, é certo, limita de modo particular a questão a ser investigada. Ou seja, quando se fala de conhecimento, fala-se na perspectiva, na limitação-delimitação, na fronteira do conhecimento que é inconsciente, e isto basta para a formulação de um paradoxo que pode ser, no momento, expresso pelas aposições: conhecimento inconsciente, inconsciente do conhecimento, consciência inconsciente, inconsciência do conhecer. Aí temos a primeira fronteira, melhor dizendo, o primeiro abismo e, necessariamente, temos um primeiro ponto de escolha pessoal que implica em uma leitura particular daquilo o 
que é a ciência e daquilo o que é a pesquisa em universidade.

Voltando à questão de o leitor aluno, após a leitura ter-se-á uma "catarse" e conseqüentemente duas alternativas: a refuta e/ou a aceitação desse "novo". No caso de haver a aceitação do texto, o aluno estará pronto para "atravessar o outro lado do rio", como ressalta Serres (1991:29) em sua obra "Le tiers instruit":

Partir, sair, se deixar um dia seduzir. Tornar-se vários, desbravar o exterior, bifurcar alhures. Eis as três primeiras estranhezas, as três verdades da alteridade, as três primeiras maneiras de se expor. (tradução nossa)

O último ponto ao qual se refere aqui, para completar a trilogia deste estudo - o homem (sua subjetividade), o conhecimento (sua visceralidade), o espaço do aprender (sua disputa narcísica) — diz respeito à escola. Ou seja, quer-se ver (e ler) a escola sendo tomada em seu sentido mais abrangente, isto é, sendo tomada em seu sentido mais subjetivo, em seu aspecto de pura passionalidade, sendo tomada como o lócus privilegiado da desilusão, ou seja, sendo tomada como o local de nascimento, manutenção e desenvolvimento da experiência da sedução e da mentira. A escola, espaço onde se encenam certos jogos extremos do espírito, acaba por reduzir a grande experiência simbólica da virtude, da tristeza e do conhecimento à, não menos grande, experiência física da vertigem, da euforia maníaca e do treino mecânico controlado pelo 'reforçamento' operante (Skinner). Note-se ainda, infelizmente, que esta última linha de pensamento, muitas vezes tem sido confundida com uma abordagem política da ética do ensinar.

Cabe aqui salientar a comparação do professor com seres mitológicos como Eros e Tanatos, ou seja, Eros, o detentor da vida, da pulsão, do desejo, é capas de insuflar no professor o entusiasmo de uma aula enquanto que Tanatos representa a morte, o despreparo, o não estar nem aí para o aluno, causando uma catástrofe no ensino e na mente dos educandos.

\section{UMA POSSÍVEL RUPTURA COM O ENSINO TRADICIONAL}

Desde que haja em algum lugar o sujeito suposto saber - que eu abreviei hoje no alto do quadro por S.s.S - há transferência. (LACAN, 1990: 221).

Para isso os quatro discursos de Lacan nos servem como uma alternativa de modificar o ensino-aprendizagem vigente, causando uma ruptura com o ensino tradicional e proporcionando ou insuflando no educando o desejo de aprender, modificando, desta forma, o pensamento do aluno e incentivando-o ao pensamento crítico. Nesta última parte do artigo estaremos nos baseando em Baldino (1994).

O primeiro de seus discursos diz que governar é impossível. Este é o discurso do 
mestre, o qual é o discurso que está presente no momento inaugural quando o professor apresenta ou deixa implícito o contrato de trabalho que define o regime de promoções: número de provas, livro texto, nota de aprovação, etc.

Seguindo, temos o discurso universitário que nos diz que educar é impossível. Neste discurso, o significante-mestre exerce sua função a partir da posição da verdade, ou seja, a autoridade magistral é o fundamento que precisa ser recalcado para que o saber possa exercer sua função na posição de agente. $O$ professor aparece como prestidigitador do saber e se apresenta de preferência como cientista ou pesquisador. Esforça-se para pairar acima da autoridade magistral a que ele alude como burocracia sem importância; minimiza a discussão do contrato de trabalho e põe a promoção como conseqüência do saber adquirido.

Dando continuidade, temos o discurso do analista, que nos diz que analisar é impossível, já que marca o momento em que o professor começa a fazer aplicações da teoria dada e passa alguns exercícios para os alunos resolverem em aula. Marca também o momento da prova. A verdade desse momento é o saber organizado que, agora, não deve aparecer como tal, mas sim sob forma de uma intimidade do aluno com o objeto de conhecimento. É preciso que o exercício não seja, como costuma-se dizer, mera aplicação de fórmula, para que não se recaia no discurso do mestre.

Finalmente temos o discurso da histérica, o qual nos diz que fazer desejar é impossível. É um puro S1 que impõe ao aluno a demanda do Outro. A verdade recalcada é que o aluno precisa saber que ele precisa passar e automaticamente para isso precisa de uma nota, ou seja, se não há uma pressão não haverá o porquê de estudar e o porquê de "passar". Dessa forma, o nível simbólico da transferência aparece, então, quando o professor, em vez de ocupar o lugar do sujeito-suposto-saber que o aluno Ihe atribui, ocupa o lugar do Outro.

\section{BIBLIOGRAFIA}

BALDINO, Roberto Ribeiro. CABRAL, Tânia Cristina Baptista. Os quatro discursos de Lacan e o teorema fundamental do cálculo. II Congresso Iberoamericano de Educação matemática. FURB, Blumenau, 1994.

DOR, Joël. Introdução à leitura de Lacan: o inconsciente estruturado como linguagem. Porto Alegre: Artes Médicas, 1989.

ETCHEGOYEN, R. Horacio. Fundamentos da técnica psicanalítica. Porto Alegre: Artes Médicas, 1987.

LACAN, J. Escritos. São Paulo: Perspectiva, 1978.

O seminário, livro VIII: a transferência. Rio de Janeiro: Jorge Zahar Ed., 
1992.

. O seminário, livro $\mathrm{XI}$ : Os quatro conceitos fundamentais da psicanálise. Rio de Janeiro: Jorge Zahar Ed., 1990.

LAJONQUIÈRE. Leandro de. De Piaget a Freud: para repensar as aprendizagens: a (psico) pedagogia entre o conhecimento e o saber. Petrópolis, RJ: Vozes: 1992.

- Infância e ilusão (Psico) Pedagógica: escritos de psicanálise e educação. Petrópolis, RJ: Vozes: 1999.

LEMAIRE, Anika. Jacques Lacan: uma introdução. Rio de janeiro: Campus, 1988.

MRECH, Leny Magalhães. Um sintoma na cultura: a falência da transmissão na relação professor-aluno. Retirado do site <www.regra.com.br/educacao/afadatr.htm>, em 07/05/99.

RICHTER, Marcos Gustavo. Ensino do português e interatividade. Santa Maria: Ed. da UFSM, 2000.

SERRES, Michel. Le tiers instruit. Paris: François Bourin, 1991. 